HID 46 (2019)

\title{
SOBRE LA “REFUNDACIÓN” E INCORPORACIÓN AL CÍSTER DEL MONASTERIO DE FERREIRA DE PANTÓN (LUGO). NUEVAS LECTURAS Y OTROS TESTIGOS ${ }^{1}$
}

\author{
THE RESTORATION OF THE CONVENT OF FERREIRA DE PANTÓN \\ (LUGO) AND ITS AFFILIATION WITH THE CISTERCIANS: NEW \\ EVIDENCE AND NEW INTERPRETATIONS
}

\author{
Ana SuÁrez GonzÁLez \\ Universidade de Santiago de Compostela \\ ana.suarez@usc.es ORCID: https://orcid.org/0000-0001-5948-428X
}

RESUMEN: La mayoría de las afirmaciones sobre la "refundación" e incorporación al Císter de la abadía femenina de Ferreira de Pantón (Lugo) se basan, directa o indirectamente, en un solo diploma datado el 17 de diciembre de 1175. Esta carta, dada por desaparecida, fue editada, incompleta, en el tercer volumen de los Annales de Ángel Manrique. Considerado por muchos "documento fundacional" del cenobio, en el texto fragmentario publicado se sustentan varias aseveraciones perpetuadas en la bibliografía científica: dicho día la abadía fue restaurada o "refundada" por la condesa doña Fronilde Fernández, que intitula la pieza, y esta generosa benefactora la entregó inmediatamente a la orden cisterciense, bajo la tutela del abad Vidal y la comunidad de Santa María de Meira, una abadía de la misma diócesis. Ahora, dando voz a otras fuentes documentales, es posible un nuevo acercamiento a estos hechos y matizar la información.

Palabras ClaVe: Ferreira de Pantón (Lugo); Fronilde Fernández; Orden cisterciense; Santa María de Meira; monacato femenino.

ABSTRACT: Most discussions of the restoration of the nunnery of Ferreira de Pantón (Lugo) and its affiliation with the Cistercians are based, directly or indirectly, on one diploma dated December 17, 1175. This charter, assumed to

Recibido: 27-4-2019; Aceptado: 1-7-2019; Versión definitiva: 3-9-2019.

1. Abreviaturas utilizadas: $A I=$ Apéndice I; $A I I=$ Apéndice $I I ; A I I I=$ Apéndice III; ACL = Archivo de la catedral de Lugo; AHDA = Archivo Histórico Diocesano de Astorga; AHN = Archivo Histórico Nacional; AMFP = Archivo del Monasterio de Ferreira de Pantón; AMS = Archivo del Monasterio de Santo Domingo de Silos; AMSID = Archivo del Monasterio de San Isidro de Dueñas; RAG $=$ Real Academia Galega (Archivo).

Copyright: (C) Editorial Universidad de Sevilla. Este es un artículo de acceso abierto distribuido bajo los términos de la licencia de uso y distribución Creative Commons Reconocimiento-No-ComercialSinObraDerivada 4.0 (CC BY-NC-ND 4.0) 
be lost, was partially published in volume 3 of the Annales of Ángel Manrique. In the academic literature, two pillars of the convent's history rest on this text, widely viewed as a "foundational charter". In 1175, Countess Fronilde Fernández, the charter's protagonist, restored or re-established the convent. She immediately ceded it to the Cistercian order, placing it under the tutelage of Abbot Vidal and the monastery of Santa María de Meira, the order's first house in the diocese of Lugo. New documentary evidence now invites us to revisit and revise the familiar account of this foundation's history.

KEYWORDs: Ferreira de Pantón (Lugo); Fronilde Fernández; Cistercian Order; Santa María de Meira; nunneries.

El monasterio de San Salvador de Ferreira de Pantón ${ }^{2}$, cercano a Monforte de Lemos, en la diócesis de Lugo, es, junto a Santa María de Moreira ${ }^{3}$, también lucense, uno de los dos cenobios cistercienses femeninos gallegos con origen en el siglo XII y el único que sigue vivo ${ }^{4}$.

Un recorrido por cuanto se ha escrito sobre la casa desde el último tercio del pasado siglo muestra que la mayor parte de las afirmaciones relativas a su incorporación al Císter arrancan, directa o indirectamente, de un solo diploma. Esta carta clave, datada el 17 de diciembre de 1175 y dada por desaparecida ${ }^{5}$, aparece editada, incompleta, en el tercer volumen de los Annales de Ángel Manrique ${ }^{6}$. En el texto fragmentario publicado se sustentan varias aseveraciones perpetuadas en la bibliografía científica: dicho día la condesa doña Fronilde -Froyla, Fronilla-

2. Es la única advocación mencionada en las fuentes del periodo abordado en este trabajo, la incorporación de la casa al Císter no supuso cambio alguno en este aspecto. En 1238, se denominaba aún monasterio de San Salvador (de Ferreira de Lemos), cf. AHN, Clero secular_regular, Car. 1132, n. 21. No emplearé el vocablo "abadía" para referirme al cenobio porque no hay constancia de la existencia de abadesas entre 1175 y finales del siglo XIII, la religiosa con mayor responsabilidad en la comunidad era la priora.

3. Suárez González 2017.

4. Este artículo se inscribe en el Proyecto de investigación Libros, memoria y archivos: cultura escrita en monasterios cistercienses (siglos XII-XIII). LEMACIST, financiado por la Agencia Estatal de Investigación y el FEDER en el marco del programa estatal de fomento de la investigación científica y técnica de excelencia, subprograma estatal de generación de conocimiento (convocatoria 2017), Ministerio de Ciencia, Innovación y Universidades, Ref. HAR2017-82099-P. El trabajo no habría sido posible sin la colaboración del P. Francisco Rafael de Pascual, D. Gonzalo Fraga Vázquez, canónigo archivero del cabildo lucense cuando tuvo lugar la investigación en este centro, el P. Lorenzo Maté Sadornil, abad y archivero del monasterio de Santo Domingo de Silos, el Hno. Joaquín López Serra, archivero del monasterio de San Isidro de Dueñas, sor $\mathrm{M}^{\mathrm{a}}$ José Gómez Borja (†), archivera de la abadía de Ferreira de Pantón hasta 2016, y los responsables de los archivos de titularidad pública que facilitaron el acceso a las fuentes manuscritas imprescindibles para la realización del estudio. Agradezco a James D'Emilio que haya llamado mi atención sobre los documentos relacionados con la incorporación a la orden cisterciense de Ferreira de Pantón, animándome a estudiarlos y editarlos.

5. A propósito del maltrecho fondo documental de Ferreira, refiere D. Yáñez Neira que en 1972 encontró casualmente en un cajón del archivo "más de doscientos pergaminos" (Yáñez Neira, Rodríguez 2000, p. 245), pero ya antes de 1994 habían desaparecido algunos, como señala Fernández de Viana 1994, p. 9.

6. Manrique 1649, p. 28. 
Fernández , que intitula la pieza, "restauró" en San Salvador de Ferreira la vida monástica, y, con ocasión de esta "refundación”, la generosa benefactora entregó el monasterio al Císter, bajo la tutela del abad Vidal y la comunidad de Santa María de Meira, importante abadía cisterciense de la misma diócesis.

Por fortuna, hoy, tanto tiempo después de la publicación de los Annales, es posible completar y matizar la información relativa a los actores y las circunstancias de la -real o supuesta- "refundación" de Ferreira de Pantón en 1175. Basta con realizar nuevas lecturas y dar voz a otros testigos.

\section{MEMORIA IMPRESA (SS. XVII-XVIII)}

Fr. Antonio de Yepes se ocupa de la fundación y la incorporación al Císter de San Saluador de Ferreyra en su Coronica general de la Orden de san Benito. Las noticias forman parte de un amplio apartado dedicado a la abadía cisterciense de Meira y a sus monasterios sujetos. Sin especificar de qué fuente toma la fecha, sitúa en 1158 -Era de mil y ciento y nouenta y seys- la fábrica del cenobio femenino, por iniciativa y patrocinio la condesa Froyla Fernández, e indica que el monasterio se entregó luego debaxo de la iurisdición del Abad y Conuento [de Meira $]^{9}$.

Pero no es 1158 , sino 1175 , el año que figura en la práctica totalidad de los estudios publicados desde el último tercio del siglo pasado cuando se hace referencia a la intervención decisiva de la citada condesa en una "refundación" o "restauración" de la vida monástica en el establecimiento y al inmediato comienzo de la observancia cisterciense en Ferreira de Pantón, bajo la tutela de Santa María de Meira.

La data propuesta por Yepes se ha tenido en cuenta muy pocas veces ${ }^{10}$ porque, hasta fechas recientes, la mayor parte de los eruditos e investigadores interesados por la historia de Ferreira se han basado, directa o indirectamente, en una sola pieza documental que Ángel Manrique editó incompleta en el tercer volumen de sus Annales. El cronista elogia el florecimiento de Meira bajo el abadiato de Vidal y presta atención a la "restauración" e incorporación de Ferreira al Císter:

"Et erat in eadem Lucensi diøecesi perantiquum Conobium, duplex olim, quod sæcularis iuris effectum iniuria temporum, ad Comitissam Fronillam, illustris Ferdinandi Comitis filiam, pertinebat. Ferreyra loco nomen etiam tunc, quod ipsum permanere videmus hoc nostro æuo. Cœenobium hoc instaurare curauit Fronilla, Lectis Virginibus, ex prima nobilitate totius Regni. Has de consilio, \& assensu Lu-

7. Fronilde Fernández "formaba parte de uno de los grupos familiares más notables y conocidos de la aristocracia gallega del siglo XII" (Portela Silva 2017, p. 159).

8. Yepes 1621 , f. $327 \mathrm{v}$.

9. Ibid.

10. Sí la consideran probable D’Emilio 1996, p. 70; D’Emilio 2004, pp. 314-315 y 324 y, con más argumentos, D’Emilio 2015, p. 228 y Moure Pena 2003, p. 377, Moure Pena 2005, p. 32 y Moure Pena 2018, pp. 565-566 (remitiendo a las afirmaciones de D’Emilio). 
censis Episcopi Sanctimoniales loco destinatas Vitali Abbati tradidit ad Cisterciensem normam imbuendas..."11

A continuación, edita la mayor parte de un documento ex tabulario Ferraria:

"Quoniam ea, quæ cito fuere, obliuione quandoque cito pereunt. Idcirco pro memoria temporum conditio est adhibenda litterarum, inde ego Comitissa Fronilla Ferdinandi facio fundamentum scripturæ firmissimum Monasterio de Ferreyra de hæreditate quæ fuit de ipso Monasterio, quam ego habui ab auis et atauis meis. Concedo illam pro remedio animæ meæ et parentum meorum, Omnipotenti Deo, et sanctæ Mariæ eius genitrici, necnon et omnibus sanctis, videlicet, illis monialibus, quæ in religione sancta vouerint perseuerare, iuxta consuetudinem Cisterciensium monachorum, per manum abbatis vocati Vitalis de Meyra, et conuentus sui. Atque hoc facimus de consilio et consensu Ioannis Lucensis Episcopi. Damus ergo illis de monte Cais, vsque Silum et vsque ad Minium, etc."

A esta dispositio incompleta ${ }^{12}$ sigue en la obra la data: "Facta charta XVI Kalendas Ianuarii, Æra M. CC. XIII.”.

En la extraña expresión "facio fundamentum (sic) scriptura firmissimum" del extracto documental se basa una afirmación muy difundida en la bibliografía científica: en 1175 la condesa Fronilde Fernández restauró la vida monástica en un antiguo cenobio que le pertenecía y que por esos años se hallaba desierto o con una vida efimera, $\mathrm{y}$, con ocasión de esta "revitalización" o "refundación", el monasterio femenino se incorporó al Císter como casa sujeta a Meira ${ }^{13}$.

11. Manrique 1649 , p. 28.

12. El editor ya advierte que no la reproduce íntegramente: nam plures et ecclesias \& villas ibidem nominat (ibid.). Traducción al castellano de la pieza en Yáñez Neira 1976, p. 221; Yáñez Neira; Tobío Cendón 2000, p. 2; Yáñez Neira y Enríquez Rodríguez 2000, pp. 231-234.

13. Las palabras en cursivas proceden de Yáñez Neira (Yáñez Neira, Tobío Cendón 2000, p. 2). Se refiere también a este hecho en Yáñez Neira 1976, pp. 221-222, Yáñez Neira 1993, pp. 19-20 y Yáñez Neira, Enríquez Rodríguez 2000, p. 231. El regesto del documento $n^{\circ} 7$ de la colección diplomática de Ferreira de Pantón debida a J. I. Fernández de Viana, resultante de la unión de los fragmentos que editó Manrique, es éste: "La condesa doña Fronilda Fernández restaura la vida monástica en el monasterio de Ferreira, bajo la custodia del abad Vidal de Meira" (Fernández de Viana 1994, p. 24). En numerosos estudios publicados entre 1975 y 2017 se sitúa también en 1175 la "puesta en marcha de la fundación" (Yáñez Neira 2000, p. 231), por Fronilde Fernández y su entrega simultánea al Císter. Además de los trabajos ya citados, pueden mencionarse los siguientes: Cavero Domínguez 1998, pp. 79, 83 y 90; Cavero Domínguez 1999, p. 799; Carrero Santamaría, González García 1999, p. 1135; Alonso Álvarez 2007, p. 666; García Flores 2010, p. 35; Cendón, Chao 2012, p. 92 y Cavero Domínguez 2017, p.163. Otros estudiosos consideran que 1175 abre "una época trascendental para el monasterio de Ferreira" (Vázquez Saco 1951, p. 178), pero desligan claramente la "fundación " o "refundación" -anterior- de la incorporación al Císter, que sí fechan en dicho año. Además de Vázquez Saco 1951, cabe citar a H. Sá Bravo, que afirma: "ante el estado de pobreza y estrechez de la iglesia y cenobio, la piadosa condesa emprendió la restauración y con ello su incorporación a la orden cisterciense, que fue en el año de 1175, fecha que suele señalarse como la de fundación, cuando es la de su agregación a la reforma del Císter" (Sá Bravo 1972, p. 438). También hacen hincapié en la integración en la orden cisterciense en 1175, pero sin mencionar explícitamente una simultánea "refundación" por parte de la condesa, Enríquez Rodríguez 1998, pp. 1290-1291; Portela Silva, Pallares Méndez 2012, p. 175 y Por- 
Sin embargo, otra información importante en el mismo apartado ha pasado desapercibida. Manrique habla de otro documento de igual fecha mediante el cual la citada condesa y varios propietarios más renunciaban a sus derechos sobre el cenobio.

"Qua autem die hæc donatio facta est, eadem etiam \& omnes consanguinei, quibus pars erat in eodem Monasterio, aut ius aliquod succedendi; etiam remotum, similem aliam unanimes fecerunt, assistentibus, confirmantibusque utranque chartam Episcopis, \& Abbatibus prædictis; \&, quod mireris, præcedenti subscriptione trium Abbatum, quam subscriptio Pontificum subsequitur, sic enim habet: Abbas Agidius de Superado, confirmat. Abbas Vitalis de Meyra, confirmat. Abbas Martinus de Melone, confirmat. Domnus Petrus, Compostellanus Archiepiscopus, confirmat. Domnus Ioannes, Lucensis episcopus, confirmat. Domnus Aldephonsus, Auriensis Episcopus, confirmat. Comes Gometius confirmat. Comes Vrgellensis confirmat, etc." 14

$\mathrm{Y}$, tras dar a conocer estas suscripciones, en un orden peculiar, llama la atención sobre la participación de una abadesa-María Sánchez-en las disposiciones de los dos diplomas, aunque la citada no era superiora de Ferreira de Pantón, como cree erradamente, sino de una casa benedictina orensana: San Salvador de Sobrado de Trives:

"Prima Abbatissa loco præfecta fuit Maria Sanctii è Comitissæ Fronillæ consanguineis, Comitissa \& ipsa: nam \& partem, quam in Monasterio habebat, donat vtraque charta, \&..."15

A finales del setecientos, en el volumen XLI de la España Sagrada, M. Risco se refiere a la grande opinión y fama del abad Vidal de Meira, se ocupa de la "Condesa D. Fronilde", "Señora del Monasterio de Ferreyra en tierra de Lemos"16, y cita también dos "escrituras" diferentes, ambas otorgadas el 17 de diciembre de $1175^{17}$. En una,

"Esta Señora pues, y la Condesa Doña Sancha Fernández, la Abadesa Doña María Sánchez, D. Gil, el Conde D. Velasco, D. Fernando, y Doña Teresa del mismo apellido de Sánchez, y Doña María, y D. Fernando Osóriz precediendo la autoridad y

tela Silva 2017, pp. 157 y 163 . Sobre la probable fundación a mediados de la centuria decimosegunda, remito a las afirmaciones de Yepes y a los estudios citados en la nota 10 .

14. La colección documental parcial de Meira-formada sólo por instrumentos "particulares" anteriores a 1237- que contiene la tesis doctoral inédita de Domínguez Casal 1952, pp. 56-57 (nº 67) y la colección diplomática de Ferreira de J. I. Fernández de Viana 1994, p. 24 (nº 7) incluyen un documento resultado de unir al fragmento "Quoniam ea, quæ cito fuere.... Æera M. CC. XIII." las suscripciones "Abbas Agidius de Superado (...) Comes Vrgellensis confirmat, etc.".

15. Manrique 1649, p. 28.

16. Risco 1798 , pp. 31-32.

17. A la información proporcionada por Risco hacen referencia Yáñez Neira 1976, Yáñez Neira 1993, pp. 19-20, Yáñez Neira, Tobío Cendón 2000, Yáñez Neira, Enríquez 2000, p. 231, Moure Pena 2003, pp. 378-379; D’Emilio 2004, pp. 314-315; Moure Pena 2005, p. 33 y D’Emilio 2015, pp. 229-230. 
el consentimiento de D. Juan Obispo de Lugo, ofrecieron el expresado Monasterio a Dios, y a D. Vidal, Abad de Meyra, prometiendo que jamás pretenderían tener parte en él como en cosa que perpetuamente debía ser del Orden del Císter. Hízose escritura de esta donación en 17 de diciembre de dicho año de 1175 y la firmaron todos los donantes, y luego los Prelados D. Pedro, Arzobispo de Compostela, Don Juan, Obispo de Lugo, y D. Alonso de Orense. Síguense en las confirmaciones el Conde de Urgel, y Don Gómez, y luego los Abades D. Vermudo, D. Gil que lo era de Sobrado, D. Vidal de Meyra, y D. Martín de Melón"18.

Y en la otra, "del mismo día, mes y año":

"la referida Condesa Doña Fronilde hizo una copiosa donación al Monasterio de Ferreyra, y asimismo al de Meyra, y a todas las Monjas, quce in religione sancta voluerint perseverare juxta consuetudinem Cisterciensium Monachorum per manum abbatis vocabulo Vitalis de Meyra, \& per consensum, \& per prceceptum Joannis Lucensis Episcopi. A la donación de D. Fronilde se junta la de Doña María Sánchez que se llama abadesa de Sobrado, y ofrece la parte que tenía en las Iglesias de Ferreyra. Hablan luego las dos Señoras y dicen que dan todo lo expresado en la Escritura al Orden del Císter y a D. Vidal, Abad primero de Meyra, y a todos los sucesores en la Abadía"19.

La relación con los dos instrumentos de idéntica fecha citados en los Annales es manifiesta, pero también resulta evidente que Risco no se basó en Manrique. Las noticias en la España Sagrada permiten completar, puntualizar y corregir en parte la información transmitida por el cronista cisterciense. En el primero de los regestos se pone de manifiesto que la condesa Fronilde Fernández no fue la única "promotora" de la entrega del cenobio a la orden cisterciense bajo la tutela de Meira, aunque sí encabeza la relación de los nueve participantes en el acto. En el segundo destaca la importancia concedida a la intervención de la superiora de Sobrado de Trives: el documento sintetizado recogía voluntad y dispositiones de dos benefactoras distintas, la condesa Fronilde y la abadesa María Sánchez. Por último, no hay mención alguna a una "fundación" o "restauración” del cenobio por Fronilde Fernández en 1175; de los dos resúmenes se desprende que ambas piezas son cartas de donación, no "documentos fundacionales" o "refundacionales" de un establecimiento desierto o en declive.

\section{MEMORIA INÉDITA DEL SIGLO XVIII}

A mediados del setecientos se compuso la Synopsis, seu brebis notitia monasteriorum Congregationis Hispanica Cisterciensis, Castella et Legionis dictoe, et

18. Risco 1798, pp. 31-32.

19. Risco 1798 , p. 32. 
alias Santi Bernardi ${ }^{20}$, atribuida al P. Basilio Mendoza ${ }^{21}$. En la "Notitia Monasterii monacharum Sancti Salvatoris, dicti de Ferreyra, Ordinis Cisterciensis"22, y al igual que en los Annales - ¿su fuente?-, se considera que en 1175 tuvo lugar una "fundación" promovida por la condesa Froyla o Fronila:

"Anno Domini 1175 prima huius domus fundamenta facta sunt, ut regula S. P. Benedicti secundum institutum cisterciense ibidem profiteretur, id quod a fundatrice cautum fuit, sicuti etiam, quod abbati Meyrensis monasterii obedientiam exhibererit. Porro monasterium erexit egregia et clarissima foemina comitissa Froyla, aut etiam Fronila dicta, regio sanguine sata, quipe qu $c$, aut filia, aut saltem proxime consanguinea Alphonsi regis Legionensis habeatur..."23

Mayores novedades guarda la Colección diplomática y memorias para la Historia de la Ciudad e Yglesia de Lugo ${ }^{24}$, resultado de la ambiciosa empresa histórico-diplomática desarrollada "por el canónigo don Joseph Vizente Piñeyro"25, capitular de la catedral lucense entre 1761 y 1775 , antes de formar parte del cabildo compostelano ${ }^{26} \mathrm{y}$, posiblemente, la obra de la que, directa o indirectamente, se sirvió Risco ${ }^{27}$.

La monumental colección de José Piñeiro y Cancio -en adelante, Memorias-, de más de tres mil folios, se reparte en cinco heterogéneos volúmenes en los que destacan los escritos de numerosos colaboradores o corresponsales que enviaron al erudito noticias, extractos, transcripciones de diplomas, planos, reproducciones de inscripciones, etc. El proyecto se sitúa en la línea de otros coetáneos mucho más conocidos, como, en el ámbito hispano, el de la Diplomática Española, promovido por la Congregación benedictina de San Benito de Valladolid y planteado a imitación de las exitosas iniciativas análogas de los maurinos ${ }^{28}$. La información recopilada por Piñeiro es ingente y, aunque predomina la de carácter histórico, obtenida a partir de diplomas - de muchos de los cuales se incluyen transcripciones inéditas-, no faltan las aportaciones hagiográficas y litúrgicas. Fuente esencial

20. Título en AMSID, Ms. sin signatura, f. [1], p. 239 (paginación reciente estampillada).

21. Sobre el P. Basilio Mendoza (†1790) y su Synopsis, Muñiz 1793, pp. 338-339 y De Pascual, Domínguez 2018, pp. 39-51. El texto latino permanece inédito y recientemente ha visto la luz una traducción al castellano (Domínguez 2018, pp. 52-239).

22. AMSID, Ms. s/s, p. 39 (paginación coetánea), p. 277 (paginación reciente estampillada).

23. AMSID, Ms. s/s, p. 40 / p. 278.

24. ACL, sin signatura.

25. Así aparece identificado el autor en los epígrafes que figuran en los lomos de los cinco volúmenes.

26. Doctoral segundo de la catedral lucense desde el 21 de febrero de 1761, cesó como canónigo al tomar posesión de una canonjía en la de Santiago de Compostela el 16 de noviembre de 1775 (Molejón Rañón 2003, pp. 112-123).

27. Así lo cree Vázquez Saco 1951, p. 180.

28. Para una primera aproximación a este proyecto es útil Fernández Flórez 1993, pp. 120-121. No he podido evitar relacionar con esta iniciativa la obra compiladora de Piñeiro, y más teniendo en cuenta las características de los materiales que Fr. Domingo Ibarreta, director del proyecto hasta 1782, reunió con este fin y que guarda el Archivo del Monasterio de Santo Domingo de Silos (AMS, Diplomática española). 
para el conocimiento de la diócesis de Lugo, principales instituciones -como la catedral-, monasterios vivos y desaparecidos, etc., su valor aumenta, además, si tenemos en cuenta que numerosos instrumentos originales que sirvieron de modelo a las copias insertas en las Memorias o han desaparecido o se ignora su paradero.

En el primer volumen, dentro de la "razón de los conventos y monasterios que antiguamente hubo en este obispado de Lugo"29, Piñeiro se detiene en el Monasterio de Santa María de Ferreyra, que es de monxas bernardas ${ }^{30}$. Estas páginas dedicadas a Ferreira son autógrafas y en ellas recoge numerosas noticias de interés sobre el devenir del cenobio, con apoyo explícito en los papeles de su archivo, advierte, y en instrumentos de la abadía de Meira ${ }^{31}$.

Sus resúmenes de escrituras permiten, además de un acercamiento a las vicisitudes del monasterio, conocer la composición de un fondo documental que ha llegado a nuestros días muy mermado, pues, a veces, el canónigo precisa la tradición y la ubicación de las piezas diplomáticas. Especifica, por ejemplo, que una información proviene de una copia en libro y no de un original suelto-se halla en el bezerrillo de dicho monasterio- o proporciona datos relativos a la organización e instalación de los diplomas ("en dicho archivo, en el caxón de pergaminos góticos", "en el archivo de dicho monasterio, entre los pergaminos, Número 4", etc.).

Del Becerro de este monasterio procede la siguiente noticia ${ }^{32}$ :

"En 17 de Diziembre de la era 1213 (año 1175) la condesa doña Froyla y la infanta doña Sancha Fernández, hijas del conde don Fernando Pérez de Trava y Trastamara, con aprobación y consentimiento de la actual abadesa de Sobrado de Tribis, Doña María Sánchez y de sus hermanos el conde don Balasco, don Egidio, don Fernando y doña Theresa Sánchez (hijos del expresado Sancho Núñez de la donación antezedente) y de otros varios a quienes pertenecía el patronato de este monasterio de Ferreyra le ofrecieron a Dios y a su madre Santísima y a la orden del Císter para siempre por medio del abad de Meyra don Vidal, sugetándose con todos sus haveres, derechos y pertenencias a su visita, corrección y obediencia para que tomara con cuidado el govierno espiritual y temporal de dicho monasterio según las leyes del Císter, precediendo aprobación y consentimiento de don Juan, obispo de Lugo, etc. Confirmaron este instrumento don Pedro, arzobispo de Santiago, y los obispos de Lugo y Orense, don Jil (sic), abad de Sobrado, don Vidal, abad de Meyra, don Martín, abad de Melón, doña María, abadesa de Ferreyra y otros" ${ }^{\text {"33. }}$

29. Epígrafe que forma parte de la tabla general del volumen, f. [2].

30. "Monasterio de Santa María de Ferreyra, que es de monxas bernardas" es el epígrafe que encabeza las noticias, en el f. 322r. Corresponden a Ferreira los ff. 322r-325v.

31. Aunque demuestra también conocer bien la obra de Manrique, al que cita. La información sobre Ferreira que proporciona el canónigo en este apartado de su Colección fue puesta en valor por Vázquez Saco 1951, pp. 180-182. Ensalzando la labor desarrollada por el capitular lucense, Vázquez advierte que, para reconstruir la historia medieval del cenobio, toma como referencia las noticias en el primer volumen de la Colección de Piñeiro (ibid, pp. 176-180).

32. "Becerro de este monasterio. Número 1" (ACL, Memorias, I, f. 323v).

33. ACL, Memorias, I, ff. 323r-v. La identificación de "doña María" con una abadesa de Ferreira es incorrecta. 
El resumen se ajusta al contenido de la segunda escritura citada por Manrique y la primera resumida por Risco. Ninguno de los asientos incluidos en el mismo apartado de las Memorias corresponde a un diploma intitulado por la condesa Fronilde Fernández, pero Ferreira de Pantón está presente también en otro lugar de la voluminosa Colección de Piñeiro. Los dos documentos fechados el 17 de diciembre de 1175 aparecen copiados completos en el volumen tercero, entre un conjunto de doscientos folios dedicados, como se advierte en la tabla inicial del ejemplar, a "algunas donaciones particulares desde el siglo $9^{\circ}$ hasta el referido $14^{0}{ }^{\prime 34}$. En concreto, se sitúan entre instrumentos relacionados con la Iglesia de Lugo, tal vez porque en ambos se menciona al obispo Juan, destinatario de la carta de donación que precede a las escrituras que atañen a Ferreira. A esta ubicación se debe, probablemente, que hayan pasado desapercibidos durante mucho tiempo, hasta que en 1996 James D’Emilio llamó la atención sobre su presencia en las Memorias $^{35}$. Sorprende que en los estudios sobre Ferreira publicados después, salvo, como es lógico, los debidos al responsable del hallazgo ${ }^{36}$, no se haga mención alguna a ellos.

En los ff. 424r-425v se encuentra el primer diploma resumido en la España Sagrada y segundo mencionado por Manrique. Aparece tras el epígrafe "Donación de la condesa doña Froila o Fronilde al monasterio de Ferreira. En pergamino. Año 1175. Esta señora fue la reformadora deste monasterio", un encabezamiento inapropiado teniendo en cuenta el texto íntegro de la carta (Apéndice $I I=A I I$ ). Tras la invocación simbólica y un largo preámbulo, intitulación y dispositio, queda claro que se está plasmando por escrito la voluntad de un grupo de propietarios -"Nos ad quos locus ille Santi (sic) Salvatoris de Ferraria pertinet, tam viri quam fcemin $\varkappa^{\prime \prime}$, nueve patronos, entre los cuales, abriendo la relación, aparece la referida condesa.

Precedida de la identificación "Segunda carta de donación de la condesa doña Froila Fernández que hizo al monasterio de Ferreira. Era de 1213. Pergamino", se halla -en el f. 426r-v- la carta cuyo tenor se ajusta al segundo de los resúmenes en la España Sagrada y que se asemeja a la extractada en los Annales. Tampoco en este caso la síntesis antepuesta recoge con acierto el contenido de la pieza (Apéndice $I I I=A I I I)$, puesto que el pergamino incluye dos actiones diferentes y de distinta autoría: la generosísima donación de la referida condesa y la cesión de María Sánchez, abadesa de Sobrado de Trives. En relación con la primera actio, entre las diferencias que se observan al comparar el texto de la copia del setecientos con el extracto de Manrique sobresale una: la dispositio se abre en las Memorias con las palabras "facio testamentum scripturce firmissimum" en lugar de "facio fundamentum scripturæ firmissimum" 37 .

La escritura de estas seis páginas de la Colección de Piñeiro es obra de tres manos y resultado de un trabajo en varios tiempos. Un amanuense se ocupó de

34. Parte que comprende los ff. 305-503.

35. D'Emilio 1996, p. 88, n. 5.

36. D’Emilio 2015, pp. 229-230.

37. Discordancia destacada por D'Emilio 2015, pp. 229-230. 
la transcripción del primer documento propiamente dicho $(A I I)$ en letra bastardilla redonda castellana no muy correcta, con algunas irregularidades y titubeos en la ortografía. A otro artífice - que lleva a cabo grafía de la misma modalidad, pero demuestra mayor competencia gráfica- se deben los encabezamientos que identifican las dos cartas, situados en el margen superior de los ff. 424r y 426r, la copia completa del segundo documento (Apéndice III) y dos apuntes tras el primer diploma ${ }^{38}$, ambos de gran interés.

La primera de estas notas revela que en el archivo del que toma la información había dos pergaminos con idéntico texto, salvo una pequeña variante:

"Es de advertir que hai dos tantos en pergamino desta donación al pie de la letra, y el uno dice assí: "ego, comitissa domna Maria, roboro". Y el otro dice assí: "ego, abatissa domna Maria, roboro", sin que discrepen en otra cosa alguna".

La otra advertencia, dirigida, parece, a Piñeiro, explica la incorporación, en un tiempo posterior, del segundo diploma:

"Desde el tiempo de esta donación quedó sujeto este Monasterio de Ferreira al venerable abad Vidal, célebre en santidad y virtud, y a sus sucesores, y a sus visitas y direcciones, como consta en otro pergamino del mismo día y año que la donación de arriba que queda en el archivo, que, siempre que a vuestra merced haga al caso, le remitiré una copia integral".

La tercera escritura de estas páginas -temblorosa e irregular- es la del canónigo lucense autor de la Colección, que, tras el apunte anterior del corresponsal, introduce el segundo diploma con la siguiente observación:

"Es la siguiente, que se ha remitido después de visto el presente".

La noticia de la primera carta en el volumen primero de las Memorias y su transcripción completa en el tercer tomo de la obra parten de testigos distintos, un "Becerro" 39 en el primer caso y un pergamino suelto en el segundo. No queda claro, sin embargo, en qué archivo se encontraban las piezas cuya transcripción se envió a Piñeiro. ¿En el de Ferreira? Tal vez, pero también a la comunidad de Meira, bajo cuya tutela estaba la casa femenina, interesaban ambos documentos.

38. ACL, Memorias, III, f. 425v.

39. ACL, Memorias, I, f. $323 \mathrm{v}$. 


\section{Un Pergamino de MeIra}

El Códice 114 del Archivo Histórico Nacional, es un gran Tumbo ${ }^{40}$ originario de Santa María de Meira cuyo núcleo se elaboró durante el abadiato de Felipe de Valdemoro (1614-1617) ${ }^{41}$. En él ha quedado constancia de que el archivo meirense guardaba documentos relacionados con Ferreira. El apartado dedicado a detallar el contenido del "Cajón 28. Granja de San Román de Açedre y Valdeferreyra", se abre así:

"Del monesterio de Ferreyra se hallará vn legajo en este cajón, en que están algunas visitas y electiones de abbadesas que hacían los padres abades de Meyra y otras cosas..."

Pero el escrito de mayor interés no se encuentra en los libros modernos de papel, sino entre los pergaminos sueltos de la abadía. El pequeño diploma Clero secular_regular, Car.1142, n.7 (en adelante, Clero 1142/7), carente de data explícita, transmite parte del texto del segundo documento transcrito para Piñeiro $(A$ $I I I)^{43}$. Al dorso aparecen tres notas ${ }^{44}$, dos del siglo XVI y una, probablemente, de la centuria siguiente:

(a) "(cruz). De como es filliaçión (sic) desta casa el monesteryo de Ferreyra".

(b) "Monasterio de Ferreyra".

(c) "Señal 221 " 4 .

Llama la atención, en primer lugar, el pobre aspecto del testigo (Fig. 1), con el borde inferior muy deteriorado y manchas. El pergamino -de mala calidad, pardusco por ambas caras y sin apenas diferencia entre la faz del pelo y la de la carne- mide $136 \mathrm{~mm}$ de alto x $211 \mathrm{~mm}$ de ancho. La tinta es parda, no se aprecia pautado y el espacio entre los renglones, veintiuno, es irregular.

40. El "Libro de Tumbo" o "Libro maestro de Tumbo" es característico de las casas de la Congregación cisterciense de San Bernardo de Castilla en la Edad Moderna. Al respecto, Sagalés Cisquella 1995, pp. 198-199. Un interesante ejemplar de finales del siglo XVI originario de otra abadía cisterciense gallega, Santa María de Sobrado, se aborda en Suárez González 2016.

41. Confeccionado probablemente entre el 4 de junio de 1614 y octubre de 1616 (justificación de la data propuesta en Suárez González 2017, pp. 31-33). El códice se mantuvo en uso durante mucho tiempo y recibió numerosas adiciones. En 1616 se realizó otro manuscrito de la misma naturaleza, el Libro 6476 de la sección Clero del AHN, que una nota posterior (f. [2]r) vincula a un religioso de Santa María de Nogales (León): "Sacado y trabajado por el P. Fr. Lorenzo Pérez, hijo del monasterio de Nogales". La escritura originaria de este volumen de Meira es de la misma mano que la primigenia del llamado "Tumbo de fr. Lorenzo" de la citada abadía leonesa que guarda el AHDA (sig. R-9).

42. AHN, Códice 114, f. 333v. Texto de la primera mano del Tumbo. En el citado Libro 6476 no hay información sobre el cajón 28 porque su contenido se detallaba en folios que han desaparecido.

43. Dado a conocer en D’Emilio 1996, p. 88, n. 5 y D’Emilio 2015, pp. 230-231.

44. Dispuestas perpendicularmente al texto del recto y próximas al borde del pergamino.

45. (a) En letra gótica cursiva castellana próxima a la cortesana, (b) en gótica textual y (c) en escritura bastardilla. 
El escrito está dividido en dos partes bien diferenciadas, ya a primera vista, por espacio en blanco, y relacionadas, como veremos más adelante, con las dos actiones escrituradas. La primera parte abarca los diecinueve primeros renglones (I) y la segunda (II) sólo los dos finales. Estas características hacen que la pieza parezca una pancarta.

Se aprecia la intervención de dos manos. A la primera se debe la práctica totalidad de la parte $I$ y la parte $I I$ completa y a la segunda sólo una adición en la parte $I$ (segunda mitad del renglón decimoctavo y renglón decimonoveno completo).

La escritura del primer artífice puede considerarse "no tipificada", "inferior" o "subalterna", sólo adecuada para usos de la vida cotidiana y obra de alguien no experto ni profesional en labores gráficas. El módulo de los caracteres varía, incluso, dentro de una misma palabra. Con frecuencia las letras no se sitúan sobre la misma línea -imaginaria- de renglón y son frecuentes los titubeos; debido a ello, numerosos caracteres presentan diferentes formas a lo largo del texto. Es también desigual la separación entre letras y palabras y abundan los errores ortográficos. Enlaces como es y er -con empleo de $E$ alta- recuerdan los habituales en la visigótica minúscula redonda ${ }^{46} \mathrm{y}$, sin embargo, las morfologías predominantes se acercan a las protogóticas. Como sucede con estas escrituras no ajustadas a norma, el conjunto resulta difícil de datar. En el pequeño fondo diplomático de Ferreira que ha sobrevivido sólo encontramos un documento original con escritura tan irregular y desmañada, un ejemplar de carta partida de $1236^{47}$.

Por el contrario, la letra del segundo scriptor es correcta, obra de mano experta y cabe calificarla de protogótica documental. Podría datarse en un periodo muy amplio - entre el último cuarto del siglo XII y el primer tercio del XIII-; sin embargo, tomando como base conjuntos gráficos similares en otros testigos de la misma área geográfica, las mayores similitudes se advierten con los de diplomas fechados en la segunda y tercera década de la decimotercera centuria ${ }^{48}$.

El análisis de la letra indica que la pieza no se gestó c. 1175, lo que corrobora su comparación con documentos originales de 1170-1190, algunos intitulados también por la condesa Fronilde Fernández ${ }^{49}$. Este pergamino de Meira es, sin duda, más joven.

Del estudio de los caracteres internos también se desprenden datos reveladores. Intitula la primera parte la condesa Fronilde Fernández y la dispositio se abre

46. Hay que tener en cuenta la larga permanencia de la escritura visigótica en el noroeste de la Península, como se comprueba en el conjunto diplomático originario de los cenobios que conforman el campo de investigación del proyecto mencionado en la nota 4. Se constata uso de letra visigótica en libros y documentos durante la segunda mitad del siglo XII y el primer tercio del XIII. Un ejemplo librario tardío se analiza en Suárez González 2015. Teniendo en cuenta data y autora, entre los diplomas de grafía hispánica cabe destacar AHN, Clero secular_regular, Car.1082/16, fechado en 1187, que recoge una donación de la condesa Fronilde Fernández al monasterio benedictino de Ferreira de Pallares.

47. AMFP, doc. 5. Editado por Fernández de Viana 1994, pp. 26-27, no 11.

48. Como RAG, P-02-15-01, donación a Santa María de Sobrado fechada en 1214, o RAG, P-02-19-01, una venta a la misma abadía datada en 1224.

49. Caso de AHN, Clero secular_regular, Car.1750/11, carta de donación de la condesa a otra casa cisterciense, Santa María de Armenteira, fechada en 1182. 
como en la copia en las Memorias, "ego comitissa Fronili Fernandiz facio testamentum scripture firmisimum" 50 , no coincide, por tanto, con el texto difundido por Manrique: "facio fundamentum scripturæ firmissimum". La parte II recoge la cesión de la abadesa de Sobrado de Trives.

La breve participación del segundo scriptor en el primer bloque de la pieza explica una peculiaridad en la redacción: el cambio de estilo -de subjetivo a objetivo y, de nuevo, a subjetivo- en el tenor. En el texto del primer amanuense los verbos dispositivos aparecen en primera persona -“facio", "concedo", "donamus", etc.$\mathrm{y}$, sin embargo, en la adición del segundo se emplea la tercera persona del singular: "dat comitissa..."

La modificación de estilo derivada de esta intervención posterior se advierte también en la copia hecha para Piñeiro $(A I I I)$, lo que refuerza el vínculo entre el testigo de Meira y el segundo de los documentos recogidos en el manuscrito del setecientos. Pero, ¿fue Clero $1142 / 7$ el instrumento preparatorio -inmediato o remoto- del diploma que sirvió de modelo para el traslado incluido en las Memorias? Y, suponiendo, que esta haya sido, en efecto, su condición, ¿se trata de una minuta stricto sensu?

No es fácil responder. A pesar de su sencillo aspecto, el pergamino de Meira es un producto complejo, con, aparente, doble naturaleza, la de copia extractada y la de borrador. Dicho de otro modo, parece recoger una transcripción parcial -selectiva- de uno o más diplomas hecha con el fin de confeccionar otra pieza documental.

Si se concibió sólo como un instrumento auxiliar, innecesario una vez ultimada la carta definitiva, llama la atención que haya sobrevivido. El pergamino -soporte caro y escaso- se ha respetado y conservado durante siglos manteniendo aún mucho espacio libre de caracteres en el anverso y con un reverso en blanco, en el que sólo se aprecian algunas notas modernas que, como antes ha quedado patente, indican que fue guardado y tratado a lo largo del tiempo como cualquier otro documento ultimado del archivo.

En lo que atañe al tenor, faltan datos esenciales para orientar la redacción de un mundum como la data y, sin embargo, aparece un preámbulo desarrollado, fórmula prescindible en una minuta. Caracteres externos como la letra y la mise en texte tampoco corresponden a los propios de un original o primera escrituración de los hechos referidos. La grafía -torpe e irregular- del primer amanuense no es una obra rápida de un artífice experimentado que, con el único propósito de registrar los datos imprescindibles para elaborar más adelante un discurso completo, descuidó el aspecto de los caracteres. Por el contrario, parece más bien el resultado -mediocre- de un trabajo lento y dificultoso, propio de un scriptor ocasional, inseguro, vacilante, poco habituado a este tipo de labores y que, pese a dedicar a la tarea esfuerzo y tiempo, no consiguió un conjunto de calidad. Además, la presencia de una coleta $^{51}$ bajo el final del decimoséptimo renglón, para subsanar una

50. En el documento citado en la nota anterior la dispositio comienza: "facio cartulam testamenti".

51. Ostos, Pardo, Rodríguez 1997, p. 109 (332.18). 
omisión ${ }^{52}$, lleva a pensar que estaba copiando un escrito anterior ¿de un diploma único, con dos autoras y dos disposiciones diferentes? ¿De dos documentos independientes, uno intitulado por la condesa Fronilde Fernández y otro por la abadesa de Sobrado de Trives? ¿De una pancarta con, al menos, dos componentes?

Resulta difícil, asimismo, determinar para quién se confeccionó esta pieza - ¿para la comunidad de Ferreira, beneficiaria inmediata de las donaciones, o para su tutora, la de Meira?- y con qué finalidad. Tal vez para servir de instrumento auxiliar de consulta con información importante que convenía tener presente y a mano, o, lo que parece más probable, para facilitar la elaboración de un nuevo diploma, pero, en este caso, ¿para realizar sólo una pieza más completa y solemne o para unir textos documentales independientes anteriores?

\section{DONACIONES A VARIAS VOCES}

La relación entre el texto extractado en los Annales, la segunda carta de las Memorias de Piñeiro ( $A$ III) y Clero 1142/7 ( $A I$ ) es evidente. Todo lo escrito -por dos manos, en dos tiempos y a dos estilos - en el pergamino de Meira se encuentra en la segunda carta de las Memorias ( $A I I I$ ), por lo que el testigo meirense pudo intervenir de algún modo en la génesis del documento al que remite -directa o indirectamente- esta copia del XVIII. Apunto "directa o indirectamente" porque falta información sobre la edad y forma de los -posibles- eslabones intermedios, el transcriptor que trabajó para Piñeiro sólo especifica el soporte de su modelo: pergamino.

Tabla 1.

\begin{tabular}{|c|c|}
\hline A I (Clero 1142/7) & A III (Memorias, carta segunda) \\
\hline---- & $\begin{array}{l}\text { Primer preámbulo:"Custos est memorice re- } \\
\text { cordatio scripturce". }\end{array}$ \\
\hline $\begin{array}{l}\text { [Parte I, intitulada por la condesa Fronilde } \\
\text { Fernández] } \\
\left(\text { Mano } 1^{\mathrm{a}}\right) \\
\text { - Preámbulo: "Quoniam ea ... litterarum". } \\
\text { - Intitulatio, expositio, dispositio: } \\
\text { "Unde ego comitissa Fronili Fernandiz } \\
\text { facio testamentum scripture firmisimum } \\
\text { monasterio de Ferraria de Lemabus de } \\
\text { hereditate (...) ecclesia Sancti Saluatoris" } \\
\text { + (dispositio adicional de la mano 2a: "Et } \\
\text { Sanctam Eulaliam (...) in Clamosa" }\end{array}$ & $\begin{array}{l}\text { - Segundo preámbulo: "Cum ea ... littera- } \\
\text { rum". } \\
\text { - Intitulatio, expositio, dispositio: } \\
\text { "Vnde ego comitissa donna Fronili Fernan- } \\
\text { diz facio testamentum scripturce firmissi- } \\
\text { mum monasterio de Ferraria de Lemabus de } \\
\text { hereditate (...) in Clamosa" }\end{array}$ \\
\hline
\end{tabular}

52. Tres palabras: $<$ de Sancta Maria $>$ 


\begin{tabular}{|c|c|}
\hline A I $($ Clero $1142 / 7)$ & A III (Memorias, carta segunda) \\
\hline $\begin{array}{l}\text { [Parte II. Intitulada por la abadesa María } \\
\text { Sánchez] } \\
\text { - Intitulatio y dispositio: "Ego Maria San- } \\
\text { tici abatissa de Sobrado concedo monaste- } \\
\text { rio de Ferraria omnem porcionem ecclesia- } \\
\text { rum quam abeo in ecclesiis que pertinent }\end{array}$ & $\begin{array}{l}\text { Intitulatio, expositio, dispositio:"Et ego Ma- } \\
\text { ria Sancici abatissa de Superado do et conce- } \\
\text { do pro amore Dei et eius genitricis cum om- } \\
\text { nibus sanctis monasterio de Ferraria omnem } \\
\text { portione } m \text { ecclesiarum quam habeo in eccle- } \\
\text { siis quae pertinent ad Ferraria". }\end{array}$ \\
\hline ---- & $\begin{array}{l}\text { [Dispositio conjunta, especificando que las } \\
\text { donaciones se hacen a la orden cisterciense } \\
\text { a perpetuidad] } \\
\text { "Nos ergo ambas damus omnes has hoeredita- } \\
\text { tes ordini de Cistel per cuncta scecula". }\end{array}$ \\
\hline ---- & $\begin{array}{l}\text { [Cláusulas finales]: } \\
\text { "Si quis igitur ... semper maneat firmum. } \\
\text { Amen". }\end{array}$ \\
\hline ---- & $\begin{array}{l}\text { Suscripciones: } \\
\text { a) Suscripción de las autoras con directio de } \\
\text { la carta al abad Vidal de Meira y sus suceso- } \\
\text { res: "Ego donna Fronili, vna cum Maria San- } \\
\text { cici et omnis vox nostra vobis domino Vitali, } \\
\text { primus abas de Meira, et omnibus sucesori- } \\
\text { bus vestris hanc cartam quam iusimus fieri } \\
\text { propiis manibus roboramus et confirmamus". } \\
\text { b) Suscripciones de testigos: "Qui proesentes } \\
\text { fuerunt (...) testis". }\end{array}$ \\
\hline ---- & $\begin{array}{l}\text { Data: "Era M. CC. XIII. et quodum XVI Ka- } \\
\text { lendas Januarii" }\end{array}$ \\
\hline
\end{tabular}

En la tabla anterior queda patente la mayor extensión y complejidad del tenor en $A$ III. Además de la adición de otro preámbulo -breve, muy común, accesorio, innecesario-, se introduce expositio en la parte que intitula la abadesa María Sánchez, cláusulas de la sanctio, suscripciones de autoras y testigos y data cronológica. Por otra parte, las actiones de cada una de las otorgantes, que en $A$ I forman bloques cerrados e independientes, bien diferenciados por la mise en texte y el tenor, en $A I I I$ se ligan mediante la conjunción copulativa que abre la intervención de la abadesa de Sobrado de Trives: "Et ego, Maria Sancici...". La unión de voluntades se ve reforzada también por una nueva dispositio conjunta de la religiosa y la condesa que no tiene como destinataria a la comunidad de Ferreira, sino a la Orden cisterciense, y que incide en la perpetuidad de la transmisión de bienes ${ }^{53}$. Por último, llama la atención que en su suscripción -también unificada- las autoras se dirigen expresamente al abad Vidal de Meira, y no a la comunidad de Ferreira. La carta $A I I I$ no es, por tanto, un simple engrosamiento o perfeccionamiento de $A I$,

53. Lo que también aparece consignado en la primera carta de las Memorias, la emitida por los nueve patronos de Ferreira (Apéndice II). 
en ella se enlazan las dos partes autónomas del pergamino meirense y el escrito se destina al prelado de la abadía a la que la comunidad estaba sujeta.

Y ¿la tercera voz?, ¿dónde se sitúa el documento extractado en los Annales?

La comparación entre este diploma editado incompleto, el pergamino de Meira y la segunda carta de las Memorias muestra que, pese a la reseñable variante testamentum (A I y A III) / fundamentum (Annales), las expresiones que pueden interpretarse como síntesis de las propiedades concedidas por la donante y la presencia/ ausencia de data, el texto reproducido por Manrique se acerca más al de la parte I del testigo meirense que al del documento trasladado en el setecientos; carece, al igual que el instrumento plenomedieval, del prefacio breve que abre $A$ III.

La parca información impide trazar un stemma fiable. Los tres testigos-Clero 1142/7, el traslado del setecientos y el extracto en los Annales- son imperfectos: demasiado distantes de los hechos consignados el editado -incompleto- en el XVII y la copia simple del XVIII y sin data la única pieza plenomedieval del conjunto.

Cabe plantear, con reservas, que para la redacción del escrito $A I I I$, el de tenor más extenso, se tuvieron en cuenta al menos dos textos documentales previos, un diploma intitulado por la condesa Fronilde Fernández y otro, quizá muy escueto o, incluso, reducido a una simple noticia, que testimoniaba la cesión de la abadesa de Sobrado de Trives. Tal vez, la segunda carta de las Memorias tuvo como antecesor -inmediato o remoto- o bien una refacción ${ }^{54}$ o bien un "documento de documentos" en el que, además de unir actiones transmitidas con anterioridad en diplomas diferentes y plasmarlas mediante un formulario más complejo, se introdujeron nuevas disposiciones.

A la luz de lo que muestra el análisis de $A I I I$, una relectura de la carta otorgada por los nueve patronos $(A I I)$ permite apuntar que, quizá, también ésta es un instrumento compuesto. Su tenor es extraño. En la primera parte, tras invocación y largo preámbulo, aparece una intitulación colectiva -"Nos ad quos locus ille Santi Salvatoris de Ferraria pertinet, tam viri quam fæminæ"- y una dispositio en la que los propietarios donan sus posesiones en el entorno de Ferreira "ipsi domino Salvatori et sanctce Marice eius gloriossisimce matris et ordini beatissimi confesoris Benedicti". El discurso se rompe para dar paso a otra parte, con nueva intitulación -en la que se detallan los nombres de nueve donantes, entre los cuales están la condesa doña Fronilde y la abadesa María Sánchez-, y diferente dispositio, puesto que, aunque coinciden los bienes -"prcedictum arum"-, en la entrega no se hace mención genérica a una ¿comunidad? que sigue la regla benedictina, sino al abad de Meira-Vidal-y a la orden cisterciense, haciéndose especial hincapié en que la cesión al Císter es perpetua. Entre otros confirmantes, suscriben, junto al prelado meirense, los abades de dos casas de monjes blancos: Egidio de Sobrado y Martín de Melón.

54. Véanse al respecto de este tipo de documentos y las probables razones de su confección los ejemplos analizados en Calleja Puerta, Sanz Fuentes 2011 y Calleja Puerta 2014. 
$\mathrm{Si}$, en efecto, el pergamino de Meira fue un instrumento preparatorio para la consecución de la -supuesta- pieza diplomática facticia a la que podría conducir A III, ésta - ¿y también $A I I ?-$ no se confeccionó en torno a 1175, pues, como se ha argumentado en el apartado anterior, la letra de Clero 1142/7 conduce a la segunda o tercera década del siglo XIII.

\section{Entre Meira y Ferreira}

El contenido de las cartas $A I I$ y $A I I I$, fechadas el 17 de diciembre de 1175, parece indicar que su principal cometido no era consignar donaciones de distintos benefactores a Ferreira, sino dejar claro que el patrimonio del monasterio se entregaba a perpetuidad a la orden cisterciense y, a la vez, reforzar la autoridad -presente y futura- de los abades de Santa María de Meira sobre el cenobio femenino. Al respecto, considero revelador que un responsable del archivo meirense en el quinientos haya sintetizado así el contenido de Clero 1142/7 en una nota dorsal a la que ya se ha hecho mención: "De como es filliaçión (sic) desta casa el monesteryo de Ferreyra".

Sobreviven muy pocos diplomas de Ferreira datados entre 1175 y el segundo tercio del siglo XIII ${ }^{55}$, pero noticias en los Annales de Manrique, extractos y resúmenes en la Colección de Piñeiro, diversos asientos en los libros de archivo modernos de Meira y algunos documentos originales del mismo fondo demuestran que en este periodo ${ }^{56}$ la abadía a la que San Salvador estaba sujeto se vio obligada a defender sus derechos -y los de la orden cisterciense- sobre la casa femenina frente a la intromisión de magnates laicos ${ }^{57}$. Después de 1175, Fronilde Fernández continuó siendo una figura fundamental en la vida de Ferreira, como señora del cenobio. En 1180, según Piñeiro -Manrique sitúa el escrito en $1181^{58}$-, Fernando II -"por los obsequios y servicios que de ella abía recivido"- donó a la condesa y "a su monasterio" cuanto "le pertenecía en el coto de Ferreyra"59, y, en 1182, “doña Elvira, con consentimiento de su marido, don Gutierre, y de sus

55. Remito a lo advertido en la nota 5. Sólo diez de los documentos conservados en el archivo del monasterio corresponden al periodo 1175-1264 y todos se sitúan en un arco temporal breve: 1236$1264\left(\right.$ AMFP $\left.^{\circ} 5-n^{\circ} 14\right)$.

56. Se ocupan de la historia de Ferreira durante este periodo Yáñez Neira 1976, Yáñez Neira 2000 y, tomando como base la colección diplomática de Fernández de Viana y Vieites, Portela Silva, Pallares Méndez 2012, p. 177 y Portela Silva 2017, pp. 160-162 y 164-166. Para conocer el devenir de la casa hasta finales del doscientos es obligada la consulta de D'Emilio 2015, pp. 230-232, pues proporciona información muy completa, incorporando datos procedentes de documentación inédita.

57. D'Emilio 2015, pp. 230-232. En referencia a la comunidad de Ferreira, apunta Portela Silva 2017 , p. 160, que después de 1175 "en la relación con el mundo, la presencia del intermediario aristocrático seguía siendo, como antes, absolutamente dominante".

58. “Æra MCCXIX” (Manrique 1649, p. 29). El cronista edita también la directio, la exposición de motivos y parte de la disposición.

59. Los entrecomillados proceden del asiento en las Memorias I, ff. 323v-324r. Advierte Piñeiro que este documento, ahora desaparecido, se encontraba "en el archivo de dicho monasterio, entre los pergaminos, número 4". La noticia en la compilación se abre con la especificación de data y otorgante 
hijos", le cedió a ella "el derecho de patronato que le pertenecía en el monasterio de Ferreyra, iure fundationis" 60 .

Su hija Guiomar, hubo de ratificar en 1196 las disposiciones de su madre relativas a Ferreira, dejando muy claro, además, que las donaciones al monasterio habían tenido también como destinataria a la orden cisterciense y haciendo referencia expresa a la autoridad del abad meirense sobre la comunidad ${ }^{61}$.

En el Códice 114 del AHN, ha quedado constancia de que en el año 1201,

“era 1239, la condesa doña Eluira y doña María Osores dieron la parte que tenían en el monasterio de Ferreyra a la orden de Císter, con condición que aya siempre en él mugeres que siruan a Dios" ${ }^{2}$.

Pero las dificultades de Meira para salvaguardar tanto los derechos de la orden como su propia potestad sobre Ferreira aumentaron en los años siguientes. Sólo así se explica el pleito entre la comunidad meirense y don Fernando Gutiérrez, hijo de la citada doña Elvira.

Procedente del archivo de Meira, se conserva un documento original ${ }^{63}$, fechado en $1238^{64}$, con los términos del acuerdo final

"inter abbatem et conuentum de Meira, ex una parte, et domnum Ferrandum Guterri, ex altera, super iure quod predicti abbas et conventus de Meira habent et habere debent in monasterio Sancti Saluatoris de Ferraria de Lemos" ${ }^{\prime \prime 5}$.

La relación de comparecientes que, encabezados por el obispo de Lugo, Miguel, acompañaban a los litigantes, da idea de la importancia del pleito y la avenencia. En el Tumbo de Meira se recuerda así:

"Era de 1276. Se trataua pleito entre este monasterio de vna parte y don Fernando Gutiérrez de la otra sobre el derecho que el dicho monasterio tenía en el monasterio de San Saluador de Ferrera.Y el dicho Fernando Gutiérrez de su boluntad se aparta dél y entrega las llaues al abbad de Meyra. Y el abbad le entregó a doña

y concluye con la transcripción de parte de la dispositio; reproducida, con variantes, por Vázquez Saco 1951 p. 179 y Fernández de Viana 1994, p. $25\left(\mathrm{n}^{\circ} 8\right)$.

60. Extractos de la noticia en las Memorias, I, f. 323v. Piñeiro indica que su fuente es "el becerri1 lo de dicho monasterio". Un regesto, con mención de las referencias al documento anteriores a 1994, en Fernández de Viana 1994, pp. 25-26 (nº 9). Sobre esta cesión del derecho de patronato por parte de la condesa Elvira Osórez, D’Emilio 2015, p. 230.

61. Ahora, parece, desaparecida, la carta fue editada por Manrique 1649, p. 29, de quien toma el texto Fernández de Viana 1994, p. 26 (n 10). Ofrece Piñeiro un regesto, advirtiendo que su fuente es un "Becerro" (Memorias, I, f. 323v). Análisis detallado del contenido del diploma en Portela Silva 2017, p. 161.

62. AHN, Códice 114, f. 335r. A diferencia de la cesión de Elvira Osórez escriturada en 1182, la destinataria no es una domina de Ferreira, sino la orden cisterciense.

63. AHN, Clero secular_regular, Car.1132, n. 21, carta partida por $a b c$.

64. Sólo se especifica el año: "Era $\mathrm{M}^{\mathrm{a}} \mathrm{CC}^{\mathrm{a}} \mathrm{LXX}^{\mathrm{a}} \mathrm{VI}^{\mathrm{a}}$ ".

65. En una nota dorsal del seiscientos se sintetiza así el contenido: "renunció vn seglar en el abbad de Meyra el derecho que tenía del monasterio de Ferrera". 
Millia, la qual se obligó de defender al dicho monasterio de Ferreyra y sus vienes, y estar en todo subjecta al abbad de Meyra, etc... ${ }^{66}$

Del gobierno espiritual se ocupará el abad de Meira y doña Milia, esposa del magnate, administrará lo temporal. Esta responsabilidad de "domna Milia, custos et domina monasterii de Ferraria" ${ }^{97}$ queda patente en varias escrituras de trasmisión de bienes fechadas entre 1242 y $1264^{68}$. Si es correcta la información que, al respecto, incluyen las Memorias de Piñeiro ${ }^{69}$, el 23 de noviembre de 1263 ya había tenido lugar un nuevo acuerdo entre el abad de Meira -Aimerico- y la misma familia, por el cual el prelado meirense reconocía al hijo de doña Milia, Andrés Fernández, su mujer, Mencía González, y su hija, también llamada Milia,

"por los días de su vida, en préstamo y encomienda, su lugar de Ferreyra, que ia tenía dicha su madre, doña Milia Fernández, con todos los derechos y patronatos que le pertenecían en tierra de Lemos; con la condición de proveher a la subsistencia del monasterio, no haviendo en él más que las seis monjas con la priora, cuia institución o deposición quedaría al arbitrio del abad de Meyra, como así mismo el hazer que se observase el instituto del Císter".

$* * *$

Esclarecer cuanto se relaciona con el origen, primeros tiempos e incorporación al Císter del monasterio de Ferreira de Pantón resulta complicado debido a la escasez de diplomas coetáneos supervivientes y a la necesidad de recurrir, para suplir en parte esta laguna de información, a piezas modernas, demasiado alejadas de los hechos consignados y cuya tradición y fiabilidad no es fácil determinar ${ }^{70}$.

66. AHN, Códice 114, f. 334r-v. El redactor de la noticia advierte que su fuente es un libro de archivo: "Libro de donaciones, número 561". También Piñeiro prestó atención a esta escritura, pero su resumen contiene errores. Considera que el pacto se estableció entre el abad de Meira, don Aimerico, y “doña Mencía, muger del conde don Fernando Gutiérrez Ossorio, pactando que su madre doña Milia poseihese pacíficamente el monasterio de Ferreyra por los días de su vida vajo algunas condiciones y reservando el abad para sí y sus sucesores el govierno y potestad espiritual” (ACL, Memorias, I, ff. 324v-325r). Indica el canónigo que la pieza se hallaba "en el Archivo de Meyra, caxón de San Román de Azedre, número 220" y en una nota del seiscientos en el reverso del pergamino consta la misma signatura (“señal 220”). Vázquez Saco 1951, p. 179, reproduce la noticia errada de Piñeiro. En él se basa D. Yáñez, que da por desaparecido el diploma (Yáñez Neira 1976, pp. 226-227). Este importante instrumento ha pasado desapercibido, posiblemente, por pertenecer al fondo meirense. Ausente, por su fecha, de Domínguez Casal 1952 (véase la nota 14), tampoco forma parte de la Colección diplomática publicada por Fernández de Viana 1994 y, salvo en D’Emilio 2015, p. 231, no hay mención alguna a él en las últimas aproximaciones históricas a Ferreira.

67. Intitulación de AMFP 9, fechado en noviembre de 1247.

68. AMFP 6 (1242), 7 (1244), 9 (1247), 10 (1250), 11 (1253), 13 (1261) y 14 (1264). Editados por Fernández de Viana 1994, pp. 27-34 ( $\mathrm{n}^{\text {os }} 12,13,15,16,17,19$ y 21).

69. En ACL, Memorias, I, ff. 324v se da noticia de este "pergamino cortado por a, b, c", fechado el 23 de noviembre de 1263 que guardaba el archivo del monasterio de Ferreira. De Piñeiro toma la información Vázquez Saco 1951, p. 179, y, de Vázquez, Yáñez Neira 1976, pp. 226-227. Resumen en Fernández de Viana y Vieites p. 34 ( $\left.n^{\circ} 20\right)$.

70. Son numerosos los casos similares, como apunta Grélois 2012, pp. 51-62. 
Sin embargo, sacar a la luz, someter a crítica diplomática y comparar todos los documentos disponibles, procedentes de distintos fondos y hoy dispersos, permite, creo, establecer un sólido punto de partida para proseguir las indagaciones.

De la relectura del instrumento extractado en los Annales que sitúa el 17 de diciembre de 1175 la fundación o "refundación" del cenobio, dando voz, a la vez, a otros testigos, se desprende que Manrique editó incompleta una carta de donación y no un "documento fundacional". La rara expresión facio fundamentum scripturce firmissimum que aparece en los Annales, en lugar de facio testamentum scripturce firmissimum (AI, A III), responde, parece, a un error de transcripción. Por ello, sin negar protagonismo a la condesa Fronilde Fernández en una revitalización del establecimiento, ésta pudo tener lugar tiempo atrás ¿en 1158, como apuntaba Yepes en su Coronica? ${ }^{71}$.

Debido a las peculiaridades formales y la ausencia de data de $A I$, y a la, probable, condición de refacciones o de documentos de documentos de $A$ II y A III, textos que han llegado a nosotros, además, en copias simples muy tardías, cualquier afirmación sustentada en estas piezas es arriesgada. Sin embargo, cabe plantear como hipótesis que en torno al 17 de diciembre de 1175 tuvo lugar la entrada de Ferreira en la red cisterciense, sujeto a Santa María de Meira ${ }^{72}$, aunque los instrumentos $A I I$ y $A I I I$ no se gestaron con el objetivo de dejar constancia por escrito de este hecho, sino para consignar - ¿recordar y reforzar?- los derechos de la abadía tutora y de la orden del Císter sobre Ferreira y su patrimonio, unos derechos amenazados.

\section{APÉNDICE}

[sin data]

(a) La condesa Fronilde Fernández dona al monasterio de Ferreira-bajo la observancia cisterciense y tutelado por Santa María de Meira-numerosas heredades.

(b) María Sánchez, abadesa de Sobrado de Trives, dona al monasterio de Ferreira su parte en las iglesias que pertenecen a Ferreira.

AHN, CLERO-SECULAR_REGULAR, Carpeta 1142, n. 7. Pergamino. $136 \mathrm{~mm}$ de alto x $211 \mathrm{~mm}$ de ancho ${ }^{73}$.

Inédito

REG. D’Emilio 2015, pp. 230-23174.

71. Véanse las notas 8-10.

72. En 1174 se fecha la carta de donación fundacional de Santa María de Moreira, también subordinada a Meira. La condesa Sancha se dirige a la religiosa doña Urraca y advierte: "Do eam vobis sub tali pactu et convenientia: ut moretis in ea dum vita vixeritis ad honorem Dei et servicium et subjectionem monasterio de Meyra. Post vero mortem vestram mando eam Deo et Sancte Marie de Meyra absque ulla contradictione" (Suárez González 2017).

73. Para no repetir información, remito a la descripción y análisis de la pieza en el apartado tercero.

74. Aporta, asimismo, extractos del texto. 
CIT. D’Emilio 1996, p. 88, n. 5 y D’Emilio 2015, pp. 230-231.

(a) Quoniam ea que nuperrime fiunt quando que obliuione cito pereunt, idcirco pro memoria $/ 2$ temporum condicio est adibenda litteraru $m^{75}$. Unde ego comitissa Fronili Fernandiz facio $/ 3$ testamentum scripture firmisimum monasterio de Ferraria de Lemabus de hereditate ${ }^{14}$ que fuit de ipso monasterio, quam ego abui (sic) ab auis et atauis meis. Concedo illam pro remedio ${ }^{76} \mathrm{ani} /{ }^{5} \mathrm{me}$ mee et parentum meorum omnipotenti Deo et gloriose $\mathrm{e}^{77}$ eiusdem genitrici, necnon omnibus sanctis, $/{ }^{6}$ uidelicet, illis monialibus que in religione sancta uouerint perseuerare, iusta (sic) consuetudinem cister $/{ }^{7}$ niensium (sic) monacorum, per manum abatis uocabulo Uitalis de Meira et conuentus sui et per consensum /8et preceptum Iohannis Lucensis episcopi.

Donamus [siqui]dem mediam ecclesiam de Maninti cum exitibus suis, $/{ }^{9} e t$ cum uno seruiciale et cum suis sena[r] is et tres quartas de ecclesia [Sancti] Cipriani de Uilameli et unum $/{ }^{10}$ casale $m$ que $m$ abui de canancia quod est capud uille et [ca]s[a]le $m$ de Mato et mediam ecclesiam Sancti Martini de Silones $/{ }^{11}$ et casale $m$ de Didago Martiniz et casalem de Masidi, [et] casalem de Gandin et quartam de Sancti Adriani et medium $/ 12 \mathrm{~d} e$ Foramontanos, quarta de Guitar, quarta de [Sego]in et mediam ecclesiam de Sancto Martino de Tiulanes $/{ }^{13}$ et tota $m$ meam parte $m$ de [N]eires et mediam ecclesiam de Sancti Iacobi de Nespereira et quarta $m$ de Sancto Iuliano $/{ }^{14} \mathrm{de}$ Floren[ti] et quartam de Sancta Maria de $\mathrm{Ca}[\mathrm{li}]$ anes et quarta $m$ de Sancto Iacobo de Cas[te]lo tam $<\mathrm{d} e>$ ecclesia $/{ }^{15}$ qua $m$ de uilla et totam partem de ecclesiam (sic) Sancti Mametis et quantam ereditatem $(\text { sic })^{78}$ abeo in uilla et mediam ecclesi $/{ }^{16}$ siam (sic) de Sancto Iacobo de Pradaneda et quarta (sic) $)^{79}$ de Sancto Martino de Ualascones et medio de Papeli, ${ }^{17}$ et quarta $m$ de Sancto Iohanne de Miliarios et quidquid abeo in terra camporum in Castro uaiul (?) scilicet terciam de ecclesia de Sancta Maria $/{ }^{18}$ et quod abeo (sic) in uilla et quinta de ecclesia Sancti Saluatoris.

(Add.) Et Sanctam Eulaliam in cauto de Coea in ripa de mare $/{ }^{19}$ dat comitissa ${ }^{80}$ pro piscaria et Sanctam Marinam de Caprariis in Clamosa. ${ }^{20}$

(b) Ego Maria Santici, abatissa de Sobrado, concedo [...] / monasterio de Ferraria om$n$ em porcione $m$ ecclesiarum ${ }^{21}$ quam abeo (sic) in ecclesiis que pertinent ad Ferraria.

Al dorso: "(cruz). De como es filliaçión desta casa / el monesteryo de Ferreyra" (s. XVI, in.-med.), "Monasterio de Ferreyra" (s. XVI, med.-ex.), "Señal 221" (s. XVII).

\section{A II}

1175, diciembre, 17

Las condesas Fronilde y Sancha Fernández, la abadesa María Sánchez, Egidio Sánchez, el conde Velasco Sánchez, Fernando Sánchez, Teresa Sánchez, María Osórez y Fernando Osórez donan a Santa María de Meira y a la orden cisterciense su parte en el territorio de Ferreira.

75. Palabra enmendada. Se había escrito inicialmente "licterarum".

76. Corrección de remedium mediante tachado de um y superposición de una $o$.

77. La abreviatura era glosa, se escribió después $e$ sobre la $a$ final.

78. A continuación, dos letras raspadas.

79. No hay signo de abreviación que indique ausencia de $m$ final.

80. Corrección, inicialmente se había escrito "cometissa". 
B. Archivo de la Catedral de Lugo, Colección diplomática y memorias para la Historia de la Ciudad e Yglesia de Lugo por el canónigo don Joseph Vicente Piñeyro (c. 1775), vol. III, ff. 424r-425v.

Inédito.

REG. ACL, Memorias, vol. I, f. 323v; Risco 1798, pp. 31-32 ${ }^{81}$; D’Emilio 2015, pp. 230-231.

In Dei nomine, amen. Omnis bona inspiratio ${ }^{82}$ cordium ad autoren (sic) omnium referenda est Christum nulla enim bona voluntas, nulla pia intentio ${ }^{83}$, nullum sanctum propositum absque illo ad profectum deducitur, ipsius igitur gratia ${ }^{84}$ compuncti ipsius amore et desiderio accensi inspiracione ${ }^{85}$ ipsius amoniti spontanea voluntate deducti.

Nos ad quos locus ille Santi (sic) Salvatoris de Ferraria pertinet, tam viri quam foemince, damus et concedimus ipsi domino Salvatori et sanctce Marice eius gloriossisimce matris et ordini beatissimi confesoris Benedicti ipsum arum de Ferraria ex integro per certos terminos, videlicet, per auterium Sanctce Marice, et deinde per Casam de Maria Petri de Ribo et inde ad Matum de Peraria, et inde por unde dividitur de Panton, et venit ad pena, et transit a Castrum.

Ego comitissa donna Froila, et ego comitissa donna Santia Fernandi // (f. 424v) // et ego abbatissa donna Maria Santii et domn $u$ s Egidius Santii et e[go $]^{86}$ comes domn $u$ s Velascus Santii et ego Fernandus Santii et ego Tharasia Santii et ego Maria Osoriz et ego Fernando Osoriz omnes nos damus et concedimus prcedictum arum pro amore Dei, pro salute animarum nostrarum et parentum nostrorum, tam vivorum quam mortuorum, per autoritatem domini Ioanis Lucensis episcopi et in manibus domini Vitalis abatis de Meira et ordinis cisterciensi, salva ${ }^{87}$ in omnibus canonica iustitia ${ }^{88}$, ut ex hoc nunc et usque in scecula nullus no[s]trum ${ }^{89}$ vel posteritas nostra prcesumat particionum facere, aut dominium qucerere sed soli Deo sit et soli Deo remaneat et predicto cisterciensium ordini in perpetum (sic).

Si quis vero ex parte nostra vel alterius hoc nostum (sic) factum violare aut inquietare tentaverit indignacionem Dei omnipotentis et maledictionem parentum suorum incurrat nec partem habeat in orationibus et beneficiis quce ibi facta fuerint. In super sit maledictus // (f. 425r) // et excomunicatus et cum Iuda proditore Domini in inferno dannatus et pectet regice parti aureos mille.

Era M. CC. XIII et quotum XVI kalendas Ianuarii. Regnante rege Fernando in Legione, in Galicia in Asturiis in Astremadura. Comes de Urgelio in Limia, in Lemis, in Monteroso. Comes Gometius in Trastamar.

Ego, comitissa domna Froilla, propriis manibus roboro. Ego, comitissa domna Santia, roboro. Ego, comitissa (abatissa) ${ }^{90}$ domna Maria, roboro. Ego, domnus Egidius, roboro.

81. El documento aparece citado y resumido en estudios posteriores que se basan en la España Sagrada.

82. Enmienda de inspiracio.

83. Corrección de intencio.

84. Enmienda de gracia.

85. Enmienda de inspiratione.

86. Caracteres desaparecidos por rotura del papel.

87. Corrección en la $s$ inicial y signo de abreviación eliminado.

88. Segunda $t$ superpuesta a una $c$.

89. Borrón sobre la $s$.

90. El transcriptor explica en una nota final la razón de este texto que escribió entre paréntesis (véase el segundo apartado de este trabajo). 
Ego, comes domnus Velascus, roboro. Ego, Fernandus Santii, roboro. Ego, Theresia Santii, roboro.

Domnus Petrus, Compostellanus archiepiscopus, confirmo. Domnus Ioannis, Lucensis ecclesice, confirmo. Domnus Adefonsus, Auriensis, confirmo. Comes Urgelensis confirmo. // (f. 425v) // Comes Gomecius confirmo. Veremundus abas confirmo. Abas Egidius de Superado confirmo. Abas Vitalis de Meira confirmo. Abas Martinus de Melone confirmo.

A III

1175, diciembre, 17

La condesa Fronilde Fernández dona numerosas heredades al monasterio de Ferreira y la abadesa de Sobrado de Trives cede al cenobio su parte en las iglesias que pertenecen a Ferreira. Ambas especifican, además, que su donación tiene también como destinataria a la orden cisterciense.

B. Archivo de la Catedral de Lugo, Colección diplomática y memorias para la Historia de la Ciudad e Yglesia de Lugo por el canónigo don Joseph Vicente Piñeyro, vol. III (1775), f. 426r-v.

Inédito.

REG. Risco 1798, p. 32; REG. D’Emilio 2015, pp. 230-23191.

Custos est memorice recordatio scripturce. Cum ea quce nuperime fiunt quando que oblivione cito pereunt, idirco (sic) pro memoria temporum conditio est adhibenda literarum (sic). Vnde ego comitissa donna Fronili Fernandiz facio testamentum scripturce firmis/simum monasterio de Ferraria de Lemabus de hoereditate quce fuit de ipso monasterio, quam ego habui ab avis et atavis meis. Do et concedo illam pro remedio anim $c e$ mece et parentum meorum omnipotenti Deo et glorios $c$ eiusdem genitrici, necnon omnibus sanctis, videlicet, illis monialibus quce in religione sancta uoluerint perseuerare, iuxta consuetudine $m$ cisterciensium monachorum, per manum abatis vocabulo Vitalis de Meira et conventui eiusdem loci tam prcesentibus quam futuris et per consensum et proceptum Ioannis Luccensis (sic) episcopi.

Donamus siquidem mediam ecclesiam de Manenti cum exitibus suis, et cum uno serviciale et cum suis senariis et tres quartas de ecclesia Sancti Cipriani de Villameli, et vnum casalem quem habui de ganancia quod est caput villce et casalem de Mato et mediam ecclesiam Sancti Martini de Silones (hoi Sios) ${ }^{92}$ et casalem de Didago Martiniz et casalem de Masidi (hoi Masid) ${ }^{93}$, et casalem de Gandin et quarta $m$ de Sancti Adriani et medium de Foramontanos (hoi Feramentaos) ${ }^{94}$, quarta de Guitar, quarta de Segoin et mediam ecclesiam de Sancto Martino de Trilanes (hoi San Martin de Tribas) et totam meam parte $m$ de Nerres et mediam ecclesiam de Sancti Jacobi de Nesperera et quarta $m$ de Sancto Juliano de Florenti et quarta $m$ de Sancta Maria de Calianes et quarta $m$ de Sancto Jacobo de Castelo ta $m$ de eclesia qua $m$ de villa et tota $m$ parte $m$ de eclesia Sancti Mametis et quanta $m$ h $c$ reditate $m$ habeo in villa et mediam eclesia $m$ de Sancto Jacobo de Pradaneda et quartam de Sancto Martino de Velascones et medium de Papeli, et quartam de Sancto Joanne de Miliarios et quidquid habeo in terra camporum in Castro vajul // (f. 426v) // scilicet tertiam de ecclesia de Sancta Maria et quod habeo in villa et quarta de ecclesia Sancti Salvatoris.

91. Incluye fragmentos del texto.

92. Nota del transcriptor del documento.

93. Nota del transcriptor.

94. Nota del transcriptor. 
Et Sanctam Eulaliam in cauto de Coea in ripa de mare dat comitissa pro piscaria et Sancta $m$ Marina $m$ de Caprariis in Clamosa.

Et ego Maria Sancici abatissa de Superado (esta debía ser de Sobrado de Trivis) ${ }^{95}$ do et concedo pro amore Dei et eius genitricis cum omnibus sanctis monasterio de Ferraria omne $m$ portione $m$ ecclesiarum qua $m$ habeo in ecclesiis quae pertinent ad Ferraria.

Nos ergo ambas damus omnes has horeditates ordini de Cistel per cuncta scecula.

Si quis igitur, quod absit tam de nostro genere quam de alieno hoc nostrum factum irrumpere voluerit iram Dei omnipotentis et regiam indignationem incurrat, et cum Juda Domini traditore, et cum Datam et Abiron, quos vivos terra absorbuit, in inferno dapnantum (sic) et pro temerario ausu eidem monasterio, vel eius voci, centum libras auri persolvat et quod invaserit in quadruplum reddat. Et hoc scriptum semper maneat firmum. Amen.

Ego donna Fronili, vna cum Maria Sancici et omnis vox nostra vobis domino Vitali, primus abas de Meira, et omnibus sucesoribus vestris hanc carta $m$ quam iusimus fieri propiis (sic) mani/bus roboramus et confirmamus.

Qui prosentes fuerunt confirmant. Veremundus testis. Petrus testis. Ioannes testis. Nuno teste (sic). Martinus testis. Joannes testis.

Era M. CC. XIII. et quodum XVI Kalendas Januarii.

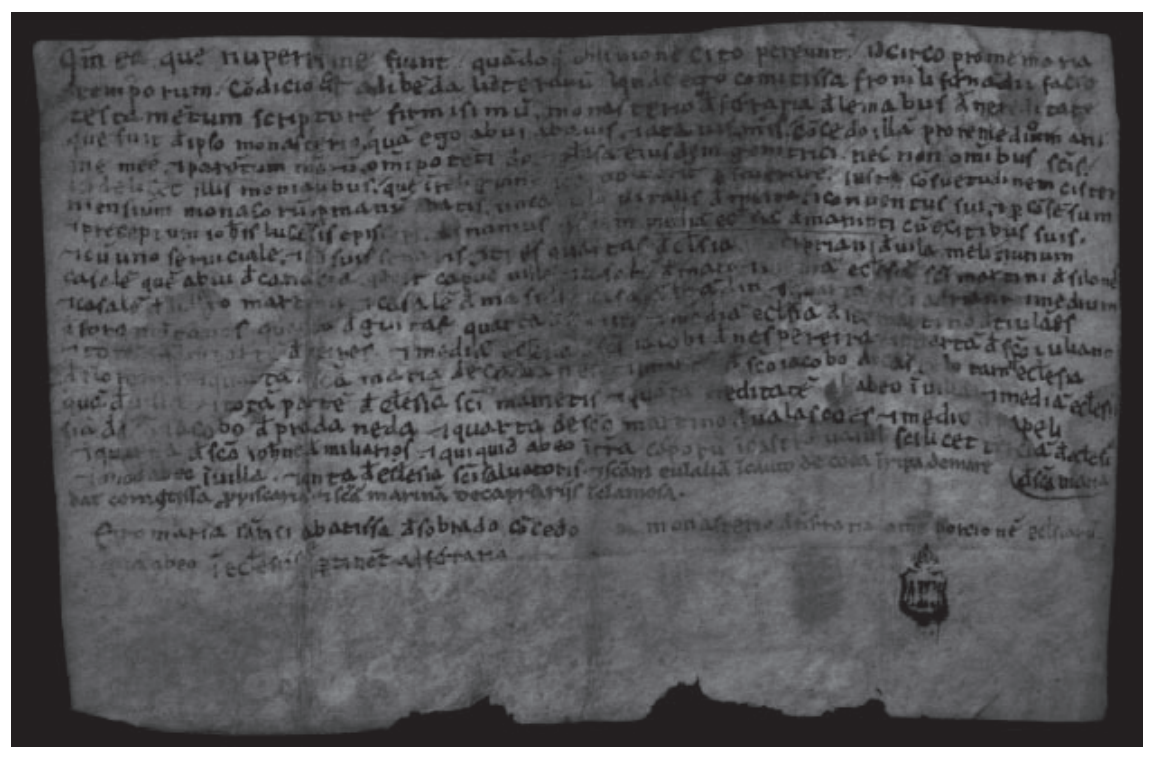

Lámina 1. Ministerio de Educación, Cultura y Deporte. Archivo Histórico Nacional, CLERO-SECULAR_REGULAR, Car.1142, N.7.

95. Nota del transcriptor. 


\section{BiBLIOGRAFÍA}

Alonso Álvarez, Raquel (2007), “Los promotores de la Orden del Císter en los reinos de Castilla y León: familias aristocráticas y damas nobles", Anuario de Estudios Medievales, 37, pp. 653-710.

Calleja Puerta, Miguel; Sanz Fuentes, M. Josefa (2011), "Fundaciones monásticas y orígenes urbanos: la refacción del documento fundacional de San Vicente de Oviedo", en Iglesia y ciudad. Espacio y poder (siglos VIII-XIII), Oviedo-León, pp. 11-41.

Calleja Puerta, Miguel (2014), "Refacciones de un diploma de Fernando I en la catedral de Oviedo", en Alma littera. Estudios dedicados al profesor José Manuel Ruiz Asencio, Valladolid, pp. 87-95.

Carrero Santamaría, Eduardo; González García, Miguel Ángel (1999), “Las dependencias monásticas de San Salvador y Santa María de Ferreira de Pantón (Lugo)", Cistercium, 217, pp. 1133-1160.

Cavero Domínguez, Gregoria (1998), "El Císter femenino en el reino de León", en II Congreso Internacional sobre el Císter en Galicia y Portugal. Actas, I, Ourense, pp. 75-105.

Cavero Domínguez, Gregoria (1999), “Implantación y difusión del Císter femenino hispano en el siglo XII”, Cistercium, 217, pp. 791-812.

Cavero Domínguez, Gregoria (2017), “El Císter femenino en los reinos de León y Castilla en los siglos XII y XIII”, en Mujeres en silencio: el monacato femenino en la España medieval, Aguilar de Campoo, pp. 149-183.

Cendón, Marta; Chao, David (2012), "El Císter en Galicia”, en El Císter en el Reino de León, León, pp. 83-115.

D’Emilio, James (1996), “Working Practices and the Language of Architectural Decoration in Romanesque Galicia: Santa María de Camporramiro and Its Sources," Arte Medievale II.10, pp. 69-90.

D’Emilio, James (2004), "The Cistercians and the Romanesque Churches of Galicia: Compostela or Clairvaux?", en Perspectives for an Architecture of Solitude. Essays on Cistercians, Art and Architecture in Honour of Peter Fergusson, Turnhout, pp. 313-327.

D’Emilio, James (2015), “Widows and Communities: Cistercian Nunneries and their Architecture in the Kingdom of León (1150-1300)", Cîteaux. Commentarii cistercienses, 66, 223-331.

Domínguez Casal, María Mercedes (1952), El monasterio de Santa María de Meira y su colección diplomática, Madrid, Universidad de Madrid (Tesis doctoral inédita).

Enríquez Rodríguez, Flora (1984), "El Real Monasterio de Santa María de Ferreira de Pantón. Estudio artístico", Cistercium, 36, pp. 125-160.

Enríquez Rodríguez, Flora (1998), "Los retablos barrocos de la iglesia del monasterio cisterciense de San Salvador de Ferreira de Pantón”, en II Congreso Internacional sobre el Císter en Galicia y Portugal. Actas, III, Ourense, pp. 1289-1302. 
Fernández Flórez, José Antonio (1993), “La Congregación benedictina de Valladolid en el siglo XVIII", en Erudición y discurso histórico: las instituciones europeas (s. XVIII-XIX), València, pp. 101-128.

Fernández de Viana y Vieites, José Ignacio (1994), Colección diplomática de Santa María de Ferreira de Pantón, Lugo.

García Flores, Antonio (2010), Arquitectura de la Orden del Císter en la provincia de Valladolid (1147-1515), Valladolid.

Grélois, Alexis (2012), "L'implantation cistercienne de part et d'autre des Pyrénées: quelques remarques préliminaires", en Espace et territoire au Moyen Âge. Hommage à Bernadette Barrière, Bordeaux, pp. 51-62.

Manrique, Ángel (1649), Cisterciensium, seu verius ecclesiasticorum annalium a condito Cistercio tomus tertius, Lyon.

Molejón Rañón, José (2003), Relación de todo el personal eclesiástico que ha conformado el cabildo catedralicio (1669-2000). Racioneros titulares (16691851) y cuerpo de beneficiados (1852-1993), Lugo.

Moure Pena, Teresa Claudia (2003), "Precisiones históricas sobre el monasterio cisterciense de San Salvador de Ferreira de Pantón (Lugo) a partir de nuevos testimonios documentales y arqueológicos", Cistercium, 231, pp. 365-389.

Moure Pena, Teresa Claudia (2005), El monasterio femenino de Ferreira de Pantón en la Edad Media. Estudio histórico-artístico, Lugo.

Moure Pena, Teresa Claudia (2018), "Ferreira de Pantón. Monasterio del Divino Salvador y Santa María”, en Enciclopedia del Románico en Galicia. Lugo. Volumen II, Aguilar de Campoo, pp. 565-578.

Muñiz, Roberto (1793), Biblioteca cisterciense española en la que se da noticia de los escritores cistercienses de todas las congregaciones de España..., Burgos.

Ostos, Pilar, Pardo, M. Luisa, Rodríguez, Elena E. (1997), Vocabulario de codicología. Versión española revisada y aumentada del Vocabulaire codicologique de Denis Muzerelle, Madrid.

Pascual, Francisco Rafael de; Domínguez García, Avelino, ed. (2018), “P. Basilio Mendoza, Congregación de Castilla (s. XVIII): Sinopsis o breve noticia de los monasterios de la Congregación española cisterciense de Castilla y León, llamada de San Bernardo", Cistercium, 271, pp. 39-239.

Portela Silva, Ermelindo (2017),'Las señoras de Ferreira. Sobre los orígenes del Císter femenino en el noroeste ibérico", en Estudios en Historia Moderna desde una visión atlántica. Libro homenaje a la profesora María Inés Carziolo, La Plata, pp. 153-166.

Portela Silva, Ermelindo; Pallares Méndez, M. Carmen (2012), "Las señoras en el claustro", en Mundos medievales. Espacios, sociedades y poder (Homenaje al profesor José Ángel García de Cortázar y Ruiz de Aguirre), I, Santander, pp. 174-186.

Risco, Manuel (1798), España Sagrada. Tomo XLI. De la santa Iglesia de Lugo: continuación de su historia desde el siglo XII hasta fines del XVIII, Madrid.

Sá Bravo, Hipólito de (1972), El monacato en Galicia, I, La Coruña. 
Sagalés Cisquella, Llorenç (1995), "Estructura institucional y legislación sobre archivos de la Congregación Cisterciense de San Bernardo de Castilla", $\mathrm{Me}$ moria Ecclesiae, 7, pp. 187-206.

Suárez González, Ana (2015), "Pergamino viejo en el archivo de Santa María de Oia: un leccionario a dos letras", Lope de Barrientos. Seminario de Cultura, 7, pp. 255-266.

Suárez González, Ana (2016), "Memoria renovada a finales del quinientos: el Tumbo partido de Santa María de Sobrado", en Dicebamus hesterna die. Estudios en Homenaje a los Profesores Pedro J. Arroyal Espigares y M $M^{a}$ Teresa Martín Palma, Málaga, pp. 512-538.

Suárez González, Ana (2017), "La donación fundacional del monasterio de Moreira (un documento recuperado)", Lucensia. Miscelánea de cultura e investigación, 55, pp. 27-38.

Vázquez Saco, Francisco (1951), “Iglesias románicas de la provincia de Lugo. Papeletas arqueológicas. Papeleta 120. Iglesia monasterial de Ferreira de Pantón", Boletín de la Comisión provincial de monumentos históricos y artísticos de Lugo, 35, pp. 176-182.

Yáñez Neira, Damián (1976), "El monasterio de San Salvador de Ferreira", Cistercium, 143, pp. 219-238.

Yáñez Neira, Damián (1993), El monasterio cisterciense y la villa de Santa María de Meira. Sintesis histórico-artística, Lugo.

Yáñez Neira, Damián; Enríquez Rodríguez, Flora (2000), “Ferreira de Pantón”, en Monasticón cisterciense gallego, II, León, pp. 230-265.

Yáñez Neira, Damián; Tobío Cendón, Rafael (2000), Ferreira de Pantón. Monasterio cisterciense en la Ribeira Sacra, León.

Yepes, Fr. Antonio de (1621), Coronica general de la Orden de San Benito, patriarca de religiosos. Tomo VII. Centuria VII, Valladolid. 